\title{
Optimization of Performance and Emission Characteristics of Diesel Engine with Biodiesel Using Grey-Taguchi Method
}

\author{
Goutam Pohit and Dipten Misra \\ Department of Mechanical Engineering, Jadavpur University, Kolkata, West Bengal 700032, India \\ Correspondence should be addressed to Goutam Pohit; gpohit@gmail.com
}

Received 18 December 2012; Revised 18 January 2013; Accepted 29 January 2013

Academic Editor: Chin-Ping Tan

Copyright ( 2013 G. Pohit and D. Misra. This is an open access article distributed under the Creative Commons Attribution License, which permits unrestricted use, distribution, and reproduction in any medium, provided the original work is properly cited.

Engine performances and emission characteristics of Karanja oil methyl ester blended with diesel were carried out on a variable compression diesel engine. In order to search for the optimal process response through a limited number of experiment runs, application of Taguchi method in combination with grey relational analysis had been applied for solving a multiple response optimization problem. Using grey relational grade and signal-to-noise ratio as a performance index, a particular combination of input parameters was predicted so as to achieve optimum response characteristics. It was observed that a blend of fifty percent was most suitable for use in a diesel engine without significantly affecting the engine performance and emissions characteristics.

\section{Introduction}

Rudolf Diesel, the father of Diesel engine, demonstrated the first use of vegetable oil in compression ignition engine. He used peanut oil as fuel in his engine. Because of the increase in the crude oil prices and limited reserve of fossils fuels, there has been a renewed focus on usage of vegetable oils as suitable alternative to diesel fuel. They are known as biodiesel, essentially an ester of vegetable oil. A brief discussion of some important research findings related to this field is presented below.

Carraretto et al. [1] conducted experiment on a CI engine firstly on a test bench and later on an urban bus. They observed that with biodiesel, there was an increase in specific fuel consumption and emission of oxides of nitrogen $\left(\mathrm{NO}_{x}\right)$. However, carbon monoxide $(\mathrm{CO})$, carbon dioxide $\left(\mathrm{CO}_{2}\right)$ emissions were reduced. Raheman and Phadatare [2] observed that Karanja oil methyl ester blended with diesel could be a suitable alternative fuel. Their emission study indicated that $\mathrm{CO}$ and $\mathrm{NO}_{x}$ were reduced by a good percentage compared to diesel. Agarwal [3] produced biodiesel from Ratanjyot (Jatropha), Karanja, Nagchampa, and Rubber by using both methyl and ethyl alcohol. He also claimed that biodiesel could be a better alternative to petroleum diesel since there was no need for engine modification.

Raheman and Ghadge [4,5] carried out experiment using Mahua biodiesel and its blends in a Ricardo E6 engine. They varied the compression ratio from 18 to 20 . It had been observed that with an increase in percentage of biodiesel, brake-specific fuel consumption increased while brake thermal efficiency decreased. Rao et al. [6] concluded from his investigation that the vegetable oils were promising alternative fuels for agricultural diesel engines. However, these vegetable oils exhibited slightly inferior performance in respect to higher smoke emission. Kalbande and Vikhe [7] studied the performance of Jatropha and Karanja biodiesel and their blends with diesel. The efficiency of Karanja biodiesel was found to be higher for B20 (20\% biodiesel and $80 \%$ diesel) and B40 (40\% biodiesel and 60\% diesel) blend among different combination of Karanja bio-diesel blend. In case of Jatropha, B60 and B80 delivered the maximum efficiency. Fontaras et al. [8] investigated the combustion and emission characteristics of biodiesel using soybean biodiesel in a diesel passenger car complying EURO 2 emission standard. They observed that there had been a problem of cold starting while using soybean biodiesel. 
Godiganur et al. [9] observed that after trans-esterification mahua oil showed a similar kind of property as that of diesel. Among the different blends, 20\% (B 20) blend was found to be the most suitable. Baiju et al. [10] produced Karanja oil ethyl ester and Karanja oil methyl ester from Karanja oil. Both of them showed good emission characteristics except presence of $\mathrm{NO}_{x}$ being on the higher side. They also claimed that the methyl ester exhibited a better performance than ethyl ester. In a study made by Sahoo et al. [11], Jatropha, Karanja, and Polanga methyl esters were blended with diesel. The maximum power output was obtained from B 50 blend. The smoke emission was found to be reduced in case of biodiesel at full throttle. However, $\mathrm{CO}$ and $\mathrm{NO}_{x}$ emission increased a bit compared to diesel.

Murugesan et al. [12] observed that methyl ester of Karanja oil could be directly used in CI engines without any modification. In case of biodiesel, brake-specific fuel consumption was found to be higher than that of diesel and the emission characteristics were reduced. They noted that the B 20 Blend was the most suitable alternative for diesel. Duraisamy et al. [13] carried out experiment by mixing the methyl esters of Jatropha, Pongamia, Mahua, and Neem seed oil. In engine performance study, the B 40 biodiesel showed a thermal efficiency almost equal to that of diesel. Emission study indicated a reduction of hydrocarbon (HC) and carbon monoxide $(\mathrm{CO})$ at any percentage mix but increased in $\mathrm{NO}_{x}$ and smoke density.

The review of the literature clearly indicated that researchers have put sincere attempt to find out the suitable alternative to diesel fuel without going through major engine modification. In most cases, they varied different input parameters, such as load, blend of fuels, and compression ratio, one at a time and observed the performance and emission characteristics of the engine. However, it may be pointed out that the number of input parameters was more than one and response of the system was not unidirectional. In other words, for a few responses lower values were better while for others higher values were better. As a result, the study became a multiresponse optimization problem that required a systematic approach to ascertain the number of experiments to be made in order to cover the entire domain of input parameters.

Based on the above-mentioned observations, an attempt was made to determine an optimum combination of input parameters that maximizes response characteristics. Design of experiment was carried out in such a fashion that the number of experiments to be carried out should be minimum while output data to be maximum. In the present investigation, Karanja biodiesel was taken as a fuel for experimentation. The performance test of biodiesel was conducted on a Kirloskar-made single-cylinder variable-compression-ratio engine.

The objective of the study was to determine the optimum blend of Karanja biodiesel and diesel oil that would result in a better engine performance along with minimum emission characteristics. Following Grey-Taguchi approach, a multiresponse problem was converted into a single one using weighting factors of grey relational analysis. Lastly, validation of the result was carried out by actual experimentation.
TABLE 1: Design factors and their levels.

\begin{tabular}{lccccc}
\hline Design factor & \multicolumn{5}{c}{ Levels } \\
& 1 & 2 & 3 & 4 & 5 \\
\hline Load in $\operatorname{kg}(A)$ & 4 & 8 & 12 & 16 & 20 \\
$\begin{array}{l}\text { Blend }(B) \\
\begin{array}{l}\text { Compression } \\
\text { Ratio }(C)\end{array}\end{array}$ & B 0 & B 25 & B 50 & B 75 & B 100 \\
\hline
\end{tabular}

TABLE 2: Fuel property table of diesel and Karanja oil methyl ester.

\begin{tabular}{lccc}
\hline Property & Diesel & $\begin{array}{c}\text { Karanja } \\
\text { bio-diesel }\end{array}$ & $\begin{array}{c}\text { ASTM } \\
\text { standards }\end{array}$ \\
\hline Specific gravity & 0.824 & 0.880 & D 3142-05 \\
Density $(\mathrm{gm} / \mathrm{cc})$ & 0.717 & 0.766 & $\mathrm{D} 1298$ \\
API gravity & 40.24 & 29.3 & $\mathrm{D} 4052$ \\
Ash content $(\%)$ & 0.060 & 0.094 & $\mathrm{D} 874$ \\
Water content $(\%)$ & 0.070 & 1.66 & $\mathrm{D} 2709$ \\
Carbon residue $(\%)$ & 0.080 & 0.530 & $\mathrm{D} 189$ \\
Flash point $\left({ }^{\circ} \mathrm{C}\right)$ & 66 & 190 & $\mathrm{D} 6450$ \\
Pour point $\left({ }^{\circ} \mathrm{C}\right)$ & 15 & 4 & $\mathrm{D} 5949$ \\
Fire point $\left({ }^{\circ} \mathrm{C}\right)$ & 72 & 395 & $\mathrm{D} 3828$ \\
Calorific value $(\mathrm{kcal} / \mathrm{kg})$ & 10056.23 & 8095.24 & $\mathrm{D} 5453-93$ \\
Viscosity $(\mathrm{cSt})$ & 4.2 & 32.3 & $\mathrm{D} 2171$ \\
Cetane number & 48 & 56.61 & $\mathrm{D} 613$ \\
\hline
\end{tabular}

\section{Methodoloy}

In order to determine the optimum blend of Karanja biodiesel and diesel on engine performance and emission characteristics of a variable compression ignition engine, three major input parameters, namely, load $(A)$, blend of fuels $(B)$, and compression ratio $(C)$ were considered to be main design factors. Each factor was further subdivided into five levels as shown in Table 1. The levels and their ranges were selected based on the previous findings as described on the open literature. All together, eight response (output) parameters were analysed; three of them belonged to performance characteristics of the engine, namely, brake power (BP), brake-specific fuel consumption (BSFC), and brake thermal efficiency (BTE). The rest five responses were emission characteristics of the engine, namely, $\mathrm{CO}, \mathrm{CO}_{2}$, $\mathrm{O}_{2}, \mathrm{NO}_{x}$, and $\mathrm{HC}$. The relevant fuel properties of diesel and Karanja biodiesel were tested as per ASTM standard (Table 2).

Since there were many input and output variables, a large number of experiments had to be conducted to cover entire domain. A well-designed experiment could produce significantly more information with fewer runs compared to an unplanned experimentation. Accordingly, Taguchi's parameter design method was adopted to understand the effect of different input parameters on response. However, conventional Taguchi method could effectively establish optimal parameter settings for single performance characteristics. Since multiple performance characteristics with conflicting goals were present, Grey-Taguchi method was adopted 
to generate a single response from different performance characteristics.

2.1. Taguchi Analysis. The Taguchi method, developed by Dr. Taguchi, involved reduction of variation in a process through robust design of experiments. A standard orthogonal array could be selected for designing the experimental plan based on the total number of degree of freedom, number of factor, and level of each factor. In the present study an orthogonal array (L25) was considered having 25 rows corresponding to the total number of tests ( 24 degrees of freedom) with 3 columns of input parameters each having 5 levels.

2.1.1. Grey Relational Analysis. Signal-to-noise ratio $(S / N)$ is a measure used in science and engineering for comparing the level of a desired signal to the level of background noise. Since the present study aimed at optimizing eight response parameters, it might so happen that the higher $S / N$ ratio for one performance characteristic may exhibit a lower $S / N$ ratio for another characteristic. Therefore, the overall evaluation of the $S / N$ ratio was required for the optimization of multiple performance characteristics. Grey relational analysis [14, 15] was found to be an efficient tool for analyzing this kind of problem. It was used to determine the key factors of the system and their correlations. The key factors were identified by the input and output sequences.

In the present paper, the experimental results were first normalized in the range between zero and one. Afterwards, the grey relational coefficients were obtained from the normalized experimental data to express the relationship between the desired and actual experimental data. Lastly, the overall grey relational grade was obtained by averaging the grey relational coefficients corresponding to each selected process response. The evaluation of the multiple process response was based on the grey relational grade. This method was employed to convert a multiple response process optimization problem into a single response problem with the objective function of overall grey relational grade. The corresponding level of parametric combination with the highest grey relational grade was considered as the optimum process parameter.

Therefore, when the target value of the original sequence was "the higher-the-better" the original sequence was normalized as follows:

$$
x_{i}(k)=\frac{y_{i}(k)-\min y_{i}(k)}{\max y_{i}(k)-\min y_{i}(k)} .
$$

When the purpose was "the lower-the-better" the original sequence was normalized as follows

$$
x_{i}(k)=\frac{\max y_{i}(k)-y_{i}(k)}{\max y_{i}(k)-\min y_{i}(k)},
$$

$y_{i}(k)$ is the original reference sequence, $x_{i}(k)$ is the sequence for comparison, $i=1,2, \ldots, m, k=1,2,3, \ldots, n$, with $m, n$ being total no of experiments and responses. $\min y_{i}(k)$ is the smallest value of $y_{i}(k)$ and $\max y_{i}(k)$ is the highest value of $y_{i}(k)$.
Here, $x_{i}(k)$ was the value after the grey relational generation. An ideal sequence was $x_{0}(k)$. The grey relational grade revealed the relational degree between the experimental run sequences $\left[x_{0}(k)\right.$ and $\left.x_{i}(k), i=1,2, \ldots m\right]$.

The grey relational coefficient $\xi_{i}(k)$ could be calculated as

$$
\xi_{i}(k)=\frac{\Delta_{\min }+\psi \Delta_{\max }}{\Delta_{o i}(k)+\psi \Delta_{\max }},
$$

where

$$
\Delta_{0 i}=\left\|x_{0}(k)-x_{i}(k)\right\|
$$

was the difference of the absolute value between $x_{0}(k)$ and $x_{i}(k) . \Delta_{\min }, \Delta_{\max }$ were the minimum and maximum values of the absolute differences $\left(\Delta_{0 i}\right)$ of all comparing sequences. The purpose of distinguishing coefficient $\psi(0 \leq \psi \leq 1)$ was to weaken the effect of $\Delta_{\max }$ when it became too large. In the present analysis, the value of $\psi$ was taken as 0.5 .

After averaging the grey relational coefficients, the grey relational grade $\gamma_{o}$ was be calculated. The higher value of grey relational grade was considered to be the stronger relational degree between the ideal sequence $x_{0}(k)$ and the given sequence $x_{i}(k)$. The ideal sequence $x_{0}(k)$ was supposed to be the best process response in the experimental layout. Thus the higher relational grade implied that the corresponding parameter combination was closer to the optimal.

2.2. Grey Relational Grade Generation. With respect to increase in blend of fuel, engine performances exhibited demising nature while emission characteristics showed increasing trend. Since reduction of engine emission could be achieved by means of different types of external equipments, such as exhaust gas recirculation (EGR), the analysis was carried out in such a way that the performance of the engine did not suffer even when diesel was replaced by blend of Karanja biodiesel and diesel oil.

Accordingly, while converting multiple grey relation grades, the value of weighting factor in engine performance was taken higher than that of emission characteristics. When appropriate, weighting factors $\beta$ was used with the sequence values; the general form of grey relational grades became

$$
\gamma_{o}=\sum_{k=1}^{n} \xi_{i}(k) \beta \gamma_{i} \ldots, \quad \sum \beta=1 .
$$

In the present case, the following values of weighting factors had been taken for different responses: brake power = 0.3 , brake-Specific fuel consumption $=0.3$, brake thermal efficiency $=0.3, \mathrm{CO}$ emission $=0.01, \mathrm{HC}$ emission $=$ $0.01, \mathrm{CO}_{2}$ emission $=0.03, \mathrm{O}_{2}$ emission $=0.01$, and $\mathrm{NO}_{x}$ emission $=0.04$.

The different sequence value of weighting factor $(\beta)$ could be specified from experience, or appropriate weights could be computed by processes such as singular value decomposition using preliminary grey relational grade values. One should note that the use of weighting factors would not be equivalent to changes in the sequence value units used or the choice made for sequence normalization $[15,16]$. 


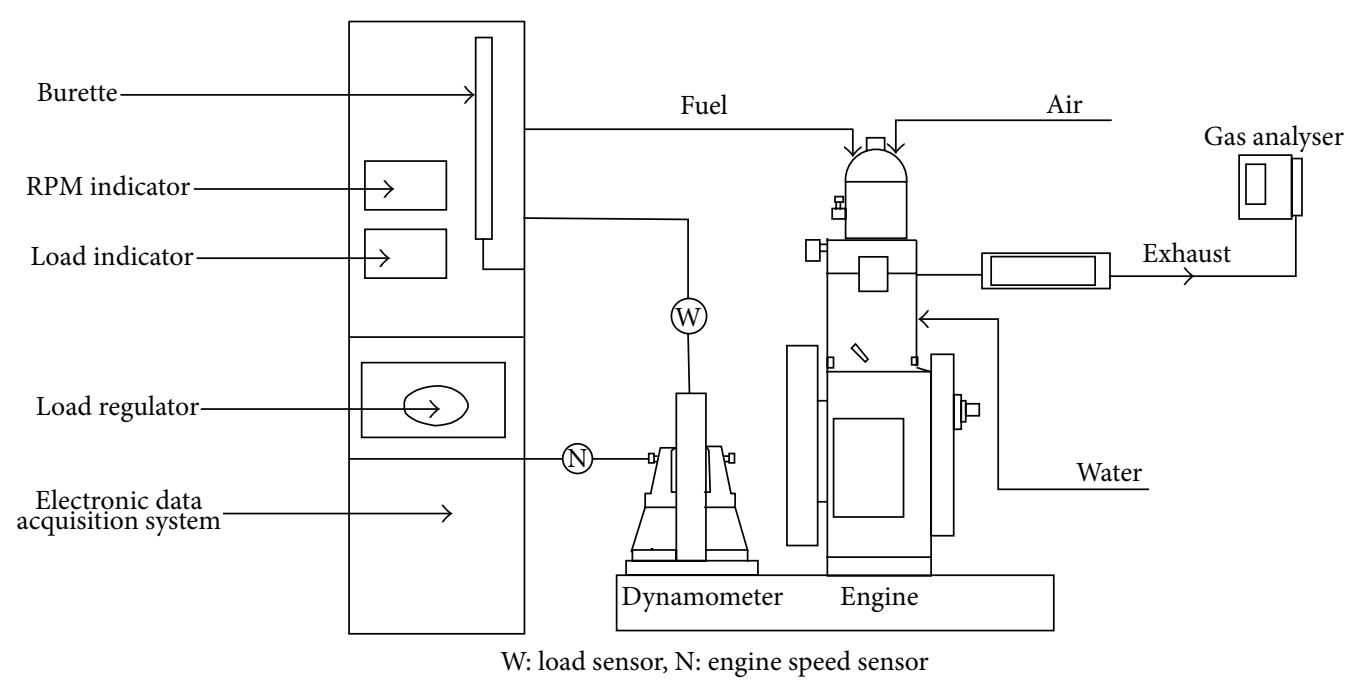

FIGURE 1: Schematic diagram of experimental setup.

\section{Experimental Setup}

The engine was directly coupled to an eddy current dynamometer using flexible coupling (Figure 1). The output of the eddy current dynamometer was fixed to a strain gauge load cell for measuring load applied to the engine. A gas analyzer was used for the measurement of carbon monoxide (CO), oxides of nitrogen $\left(\mathrm{NO}_{x}\right)$, unburned hydrocarbon $(\mathrm{HC})$, oxygen $\left(\mathrm{O}_{2}\right)$, and carbon dioxide also. $\mathrm{CO}$ was measured as percentage volume and $\mathrm{NO}_{x}, \mathrm{HC}$ was measured as nhexane equivalent, parts per million (ppm). A glass burette was provided at the fuel tank for the measurement of fuel consumption by volume per minute. For this purpose a stopwatch was used to measure the diesel and biodiesel fuel separately. The engine was subjected to different loads ( $4 \mathrm{~kg}$, $8 \mathrm{~kg}, 12 \mathrm{~kg}, 16 \mathrm{~kg}$, and $20 \mathrm{~kg}$ ), corresponding to load ranging from $20 \%$ at the lowest level and $100 \%$ at the highest level. Knowing the dynamometer shaft length $(0.185 \mathrm{~m})$, torque applied on the engine was determined. All the experiments were carried out at a rated speed of $1500 \mathrm{rpm}$ maintaining $23^{\circ}$ BTDC (before top dead centre) for both diesel and biodiesel. The experiments were conducted using B $0(0 \%$ Karanja, 100\% diesel), B 25 (25\% Karanja, 75\% diesel), B 50 (50\% Karanja, 50\% diesel), B 75 (75\% Karanja, 25\% diesel), and B 100 (100\% Karanja) under different load conditions on the engine and the results are presented in Table 4. The compression ratios (CR) were varied $(14: 1,15: 1,16: 1$, $17: 1$, and $18: 1)$. During the experiment, whenever fuel was changed, the fuel lines were cleaned and the engine was left to operate for $30 \mathrm{~min}$ to stabilize at its new condition. Figure 2 shows the whole engine assembly used for the experiment. The specifications of the engine and eddy current dynamometer are given in Table 3 . The engine exhaust (CO, $\mathrm{HC}, \mathrm{CO}_{2}, \mathrm{O}_{2}$, and $\mathrm{NO}_{x}$ ) was analyzed and calculated by AVL DIG AS 444 gas analyzer fitted with DIGAS SAMPLER at the exhaust. Specification of the gas analyzer is furnished in Table 3.
TABLE 3: Specifications of engines and instruments.

\begin{tabular}{ll}
\hline $\begin{array}{l}\text { Specifications of the engine } \\
\text { Manufacturer }\end{array}$ & Kirloskar Oil Engines Ltd. \\
Model & TV 1 \\
Type & Four stroke, water cooled \\
No. of cylinder & One \\
Rated power & $5.2 \mathrm{~kW} @ 1500 \mathrm{RPM}$ \\
Compression ratio & $11: 1$ to $18: 1$ \\
Bore & $87.5 \mathrm{~mm}$ \\
Stroke & $110 \mathrm{~mm}$ \\
Injection timing & $23^{\circ}$ before TDC \\
Method of loading & Eddy current dynamometer \\
\hline $\begin{array}{l}\text { Specifications of the } \\
\text { dynamometer }\end{array}$ & \\
Manufacturer & Saj Test Plant Pvt. Ltd. \\
Model & AG10 \\
Type & Eddy current, water cooled \\
\hline Specifications of the AVL & \\
gas analyzer & \\
Manufacturer & AVL India Pvt. Ltd. \\
Type & DiGas 444 \\
Model & 5 gas analyzer \\
\hline
\end{tabular}

\section{Results and Discussions}

Different combinations of three input variables, namely, load, compression ratio (CR), and blends were considered and eight output responses (output) were obtained. In order to search for the optimal process condition through a limited number of experiment, Taguchi's L25 orthogonal array had been selected. Therefore, total number of experiments conducted was $25(i=25)$. 


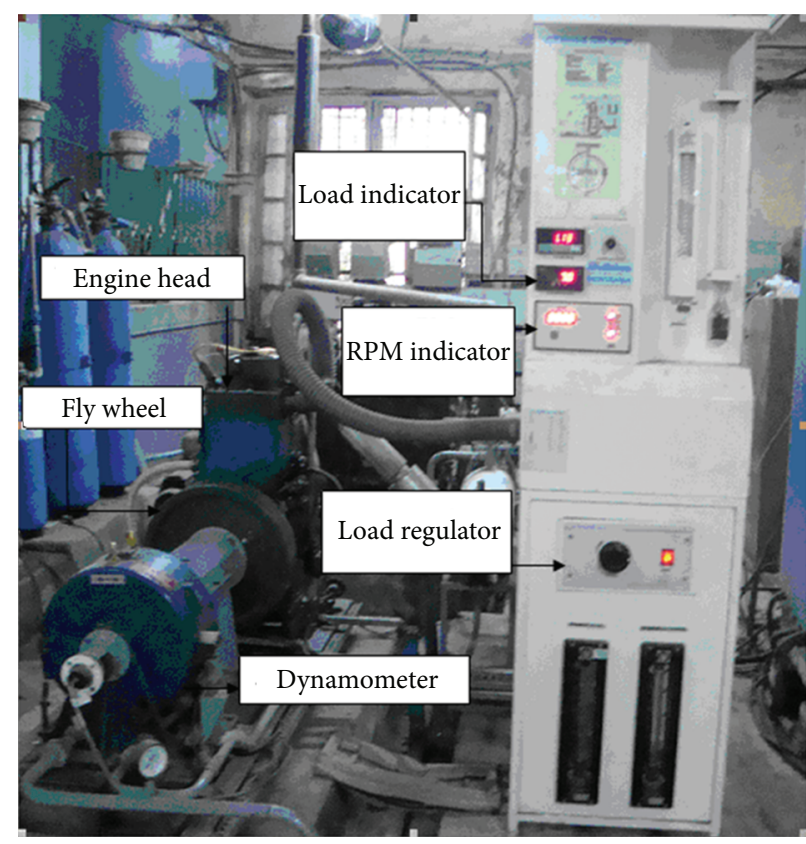

FIGURE 2: The engine assembly used for the experiment.
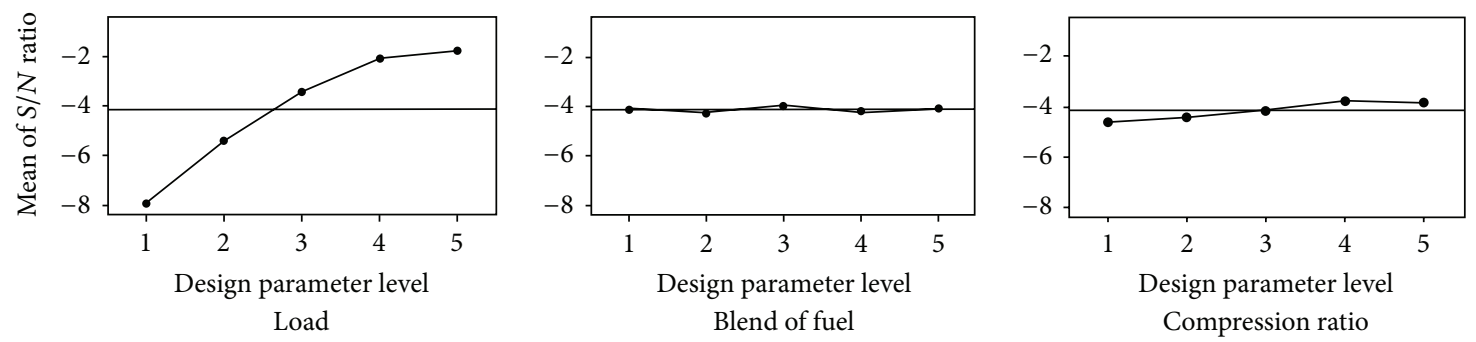

Figure 3: The main effect plots for $S / N$ ratio.

Following grey relation methods, experimental results were normalized in the range between zero to one. However, it was noted that out of eight responses shown in columns 5 to 12 of Table 4 , higher target values of three responses (BP, BTE, and $\mathrm{O}_{2}$ ) were better while those for the rest five responses, lower values were desirable. Accordingly, during normalization of data, target values of BP, BTE, and $\mathrm{O}_{2}$ parameters were calculated using (1) and the rest were obtained from (2). Furthermore, using (3), grey relation coefficients $\xi_{i}(k)$ were evaluated for each response.

In order to determine the grey relational grades (4) had been used. Considering appropriate weighing factors, the overall grey relation grade, thus, obtained is shown in Table 5.

4.1. Analysis of Signal-to-Noise Ratio. Since the traditional method could not capture the variability of the results signalto-noise ratio was introduced to analyze the grey relation grade. The signal-to-noise ratio for overall grey relation grade was calculated from (6) presented below. Since the main aim of the experiment was always to determine the highest possible $S / N$ ratio for the result, the higher-the-better (HB) criteria was sort for. A high value of $S / N$ implied that the signal was much higher than the random effects of the noise factors:

$$
S / N=-10 \log \left[\frac{1}{N_{i}} \sum_{u=1}^{N_{i}} \frac{1}{y_{u}^{2}}\right],
$$

where $i=$ experiment number, $u=$ trial number, and $N_{i}=$ number of trials for experiment $i$.

The analysis of the output response was done by minitab software. Table 6 shows the average of the selected characteristics for each level of the design factors. The graphical representation of $S / N$ ratio for three factors, load, blend, and compression ratio, is shown in the main effect plot (Figure 3 ). If the line for a particular parameter is nearly horizontal, the parameter has less significant effect on response. On the other hand, a parameter for which the line has the highest inclination will have the most significant effect. It had been observed from the plot that parameter $A$ (load) had the most significant effect among the three parameters. 
TABLE 4: Experimental results of engine performances and emissions.

\begin{tabular}{|c|c|c|c|c|c|c|c|c|c|c|c|}
\hline \multirow{2}{*}{$\begin{array}{l}\text { No. of } \\
\text { exp. }\end{array}$} & \multicolumn{3}{|c|}{ Factors } & \multicolumn{3}{|c|}{ Engine performance } & \multicolumn{5}{|c|}{ Emission characteristics } \\
\hline & $\begin{array}{c}\text { Load } \\
(\%)\end{array}$ & Blend & $\begin{array}{c}\text { Compression } \\
\text { ratio } \\
\end{array}$ & $\begin{array}{c}\mathrm{BP} \\
(\mathrm{kw})\end{array}$ & $\begin{array}{c}\text { BSFC } \\
(\mathrm{gm} / \mathrm{kw}-\mathrm{hr})\end{array}$ & BTE & $\begin{array}{c}\mathrm{CO} \\
(\% \mathrm{vol}) \\
\end{array}$ & $\begin{array}{c}\mathrm{HC} \\
(\mathrm{ppm} / \mathrm{vol})\end{array}$ & $\begin{array}{l}\mathrm{CO}_{2} \\
\text { (\%vol) }\end{array}$ & $\begin{array}{c}\mathrm{O}_{2} \\
\text { (\%vol) }\end{array}$ & $\begin{array}{c}\mathrm{NO}_{x} \\
\text { (ppm/vol) }\end{array}$ \\
\hline 1 & 20.00 & 0 & 14 & 1.223 & 632.784 & 13.521 & 0.35 & 58 & 4.8 & 14.2 & 117 \\
\hline 2 & 20.00 & 25 & 15 & 1.138 & 624.431 & 14.207 & 0.36 & 70 & 4 & 15.03 & 105 \\
\hline 3 & 20.00 & 50 & 16 & 1.200 & 509.584 & 18.029 & 0.17 & 43 & 3.8 & 15.53 & 218 \\
\hline 4 & 20.00 & 75 & 17 & 1.190 & 474.778 & 20.317 & 0.08 & 17 & 4 & 15.45 & 400 \\
\hline 5 & 20.00 & 100 & 18 & 1.150 & 599.332 & 17.734 & 0.06 & 11 & 4.2 & 15.36 & 596 \\
\hline 6 & 40.00 & 0 & 15 & 2.330 & 365.421 & 23.414 & 0.06 & 25 & 5.6 & 13.64 & 702 \\
\hline 7 & 40.00 & 25 & 16 & 2.260 & 362.915 & 24.445 & 0.07 & 41 & 5.6 & 13.33 & 726 \\
\hline 8 & 40.00 & 50 & 17 & 2.250 & 345.877 & 26.562 & 0.04 & 37 & 5.4 & 13.71 & 843 \\
\hline 9 & 40.00 & 75 & 18 & 2.342 & 337.708 & 28.564 & 0.05 & 13 & 6 & 13.15 & 963 \\
\hline 10 & 40.00 & 100 & 14 & 2.443 & 399.555 & 26.601 & 0.21 & 23 & 5.8 & 13.3 & 247 \\
\hline 11 & 60.00 & 0 & 16 & 3.403 & 271.750 & 31.485 & 0.01 & 22 & 7.3 & 11.42 & 1154 \\
\hline 12 & 60.00 & 25 & 17 & 3.351 & 293.691 & 30.207 & 0.02 & 31 & 7.4 & 11.28 & 1316 \\
\hline 13 & 60.00 & 50 & 18 & 3.475 & 271.973 & 33.780 & 0.02 & 39 & 7.2 & 11.5 & 1130 \\
\hline 14 & 60.00 & 75 & 14 & 3.282 & 327.154 & 29.485 & 0.1 & 32 & 7.8 & 10.86 & 859 \\
\hline 15 & 60.00 & 100 & 15 & 3.431 & 317.996 & 33.424 & 0.07 & 18 & 7.3 & 11.62 & 983 \\
\hline 16 & 80.00 & 0 & 17 & 4.469 & 255.027 & 33.550 & 0.02 & 7 & 1.1 & 19.25 & 123 \\
\hline 17 & 80.00 & 25 & 18 & 4.497 & 255.320 & 34.747 & 0.04 & 34 & 9.5 & 8.59 & 1240 \\
\hline 18 & 80.00 & 50 & 14 & 4.319 & 283.192 & 32.442 & 0.08 & 55 & 9.6 & 8.6 & 1298 \\
\hline 19 & 80.00 & 75 & 15 & 4.326 & 287.354 & 33.569 & 0.05 & 30 & 9.3 & 9.05 & 1337 \\
\hline 20 & 80.00 & 100 & 16 & 4.412 & 299.319 & 35.510 & 0.05 & 21 & 9 & 9.57 & 1463 \\
\hline 21 & 100.00 & 0 & 18 & 5.272 & 277.365 & 30.848 & 0.32 & 16 & 4.5 & 14.69 & 482 \\
\hline 22 & 100.00 & 25 & 14 & 5.570 & 284.662 & 31.165 & 0.73 & 84 & 11.6 & 5.29 & 1209 \\
\hline 23 & 100.00 & 50 & 15 & 5.411 & 287.639 & 31.940 & 0.3 & 65 & 11.3 & 6.06 & 1350 \\
\hline 24 & 100.00 & 75 & 16 & 5.281 & 299.598 & 32.197 & 0.17 & 39 & 11.2 & 6.57 & 1360 \\
\hline 25 & 100.00 & 100 & 17 & 5.539 & 300.610 & 35.357 & 0.12 & 29 & 11.1 & 6.81 & 1410 \\
\hline
\end{tabular}

The optimum process parameter combination corresponding to minimum emission and better engine performance was indicated by the maximum value for signal-tonoise ratio for each input parameter. Thus, from Table 6 and Figure 3, the optimum process parameter combination was found to be $A 5 B 3 C 4$, that is, load at $100 \%$, blend of fuel at B 50 (50\% Karanjal, 50\% diesel), and a compression ratio of $17: 1$.

4.2. Confirmation Tests. After the optimum process parameter was selected from the $S / N$ ratio plot, the objective was to predict the result and verify it by actual experimentation. First, corresponding to optimum level of process parameters, the estimated $S / N$ ratio $(\widehat{\gamma})$ was evaluated using the following equation

$$
\widehat{\gamma}=\gamma_{m}+\sum_{i=1}^{o}\left(\overline{\gamma_{i}}-\gamma_{m}\right),
$$

where $\gamma_{m}$ is the total mean of $S / N$ ratio, $\overline{\gamma_{i}}$ is the mean of $S / N$ ratio for optimum level, and $o$ is the number of the main design factors that affect the output responses. Following (7), the estimated value of $\widehat{\gamma}$, corresponding to $A 5 B 3 C 4$, was obtained as -1.28942 .

In order to verify our estimated value, an experiment was actually carried out with $A 5 B 3 C 4$ combination. The corresponding $S / N$ ratio of the grey relational grade was found to be -1.55769 as shown in Table 7 . The values of grey relation grade are also mentioned in the table.

In addition, an initial parameter combination of $A 3 B 3 C 3$ (load $60 \%$, blend of fuel B 50, and compression ratio 16) had been chosen as it lay at the mean level. Again, an actual experiment was conducted with this combination and the value of $\widehat{\gamma}$ thus obtained was also shown in Table 7 . It had been observed that the increase in the $S / N$ ratio from the initial parameter combination to the optimal parameters was 0.38181 .

\section{Conclusion}

In this experimental study, the effect of Karanja oil methyl ester diesel fuel blends (B 0, B 25, B 50, B 75, B 100) on engine 
TABLE 5: Calculated grey relational coefficient of all responses and grey relational grade with weightage.

\begin{tabular}{|c|c|c|c|c|c|c|c|c|c|}
\hline \multirow{3}{*}{ No. of exp. } & 0.3 & 0.3 & 0.3 & 0.01 & 0.01 & 0.03 & 0.01 & 0.04 & Total $=1$ \\
\hline & \multicolumn{8}{|c|}{ Grey relational coefficient } & \multirow{2}{*}{$\begin{array}{l}\text { Overall grey } \\
\text { relation grade }\end{array}$} \\
\hline & $\mathrm{BP}$ & BSFC & BTE & $\mathrm{CO}$ & $\mathrm{HC}$ & $\mathrm{CO}_{2}$ & $\mathrm{O}_{2}$ & $\mathrm{NO}_{x}$ & \\
\hline 1 & 0.33765 & 0.333333 & 0.333333 & 0.514286 & 0.430168 & 0.586592 & 0.43927 & 0.982634 & 0.373445 \\
\hline 2 & 0.333333 & 0.338321 & 0.340414 & 0.507042 & 0.37931 & 0.644172 & 0.417464 & 1 & 0.378041 \\
\hline 3 & 0.33642 & 0.425944 & 0.386093 & 0.692308 & 0.516779 & 0.660377 & 0.405343 & 0.857323 & 0.417256 \\
\hline 4 & 0.335961 & 0.462224 & 0.419843 & 0.837209 & 0.793814 & 0.644172 & 0.407235 & 0.697125 & 0.435404 \\
\hline 5 & 0.333886 & 0.354246 & 0.382147 & 0.878049 & 0.905882 & 0.628743 & 0.409384 & 0.580342 & 0.38742 \\
\hline 6 & 0.406158 & 0.631127 & 0.476157 & 0.878049 & 0.681416 & 0.538462 & 0.455316 & 0.532132 & 0.512611 \\
\hline 7 & 0.400941 & 0.636456 & 0.498413 & 0.857143 & 0.531034 & 0.538462 & 0.464714 & 0.522308 & 0.517082 \\
\hline 8 & 0.400289 & 0.67522 & 0.551299 & 0.923077 & 0.562044 & 0.549738 & 0.453247 & 0.479181 & 0.544128 \\
\hline 9 & 0.407054 & 0.695535 & 0.612821 & 0.9 & 0.865169 & 0.517241 & 0.47035 & 0.44177 & 0.570799 \\
\hline 10 & 0.414748 & 0.566512 & 0.552407 & 0.642857 & 0.706422 & 0.527638 & 0.465644 & 0.82704 & 0.527902 \\
\hline 11 & 0.505474 & 0.918667 & 0.732055 & 1 & 0.719626 & 0.458515 & 0.532418 & 0.39294 & 0.698241 \\
\hline 12 & 0.499549 & 0.830083 & 0.674644 & 0.972973 & 0.616 & 0.454545 & 0.538165 & 0.359259 & 0.649848 \\
\hline 13 & 0.513915 & 0.917668 & 0.864036 & 0.972973 & 0.546099 & 0.462555 & 0.529189 & 0.398474 & 0.738431 \\
\hline 14 & 0.491898 & 0.723657 & 0.646022 & 0.8 & 0.606299 & 0.439331 & 0.556175 & 0.473831 & 0.60921 \\
\hline 15 & 0.508724 & 0.749971 & 0.840584 & 0.857143 & 0.777778 & 0.458515 & 0.524418 & 0.436095 & 0.68211 \\
\hline 16 & 0.667872 & 1 & 0.848695 & 0.972973 & 1 & 1 & 0.333333 & 0.974175 & 0.853667 \\
\hline 17 & 0.673761 & 0.998456 & 0.935102 & 0.923077 & 0.587786 & 0.384615 & 0.678988 & 0.374311 & 0.827772 \\
\hline 18 & 0.638985 & 0.870237 & 0.781823 & 0.837209 & 0.445087 & 0.381818 & 0.678328 & 0.362714 & 0.730059 \\
\hline 19 & 0.640462 & 0.853863 & 0.850008 & 0.9 & 0.626016 & 0.390335 & 0.649907 & 0.355311 & 0.748546 \\
\hline 20 & 0.656787 & 0.810048 & 1 & 0.9 & 0.733333 & 0.39924 & 0.619893 & 0.333333 & 0.785884 \\
\hline 21 & 0.881464 & 0.894241 & 0.702223 & 0.537313 & 0.810526 & 0.606936 & 0.426129 & 0.642992 & 0.806833 \\
\hline 22 & 1 & 0.864383 & 0.716782 & 0.333333 & 0.333333 & 0.333333 & 1 & 0.380819 & 0.809582 \\
\hline 23 & 0.933053 & 0.852765 & 0.754927 & 0.553846 & 0.398964 & 0.339806 & 0.900645 & 0.352911 & 0.799523 \\
\hline 24 & 0.884278 & 0.809076 & 0.768489 & 0.692308 & 0.546099 & 0.34202 & 0.845036 & 0.351086 & 0.778791 \\
\hline 25 & 0.986204 & 0.805587 & 0.986363 & 0.765957 & 0.636364 & 0.344262 & 0.821176 & 0.342238 & 0.875081 \\
\hline
\end{tabular}

performance and exhaust emissions were investigated. The engine performance and emission characteristics had been analysed in the context of applicability of blend of Karanja oil methyl ester with conventional diesel as a suitable alternative fuel resource.

In the study, an attempt was made to optimize the engine responses comprising of eight different parameters when three input parameters were varied simultaneously. Since the investigation clearly indicated possibility of a large number of test combinations, design of experiment was carried out using Taguchi method to limit the number of experiments by the formation of orthogonal array, yet without sacrificing significant information.

Complexity of the optimization problem was evident from the fact that the responses were not unidirectional. Subsequently, multiresponse problem was converted into a single one with the application of weighting factors of grey relational analysis and optimum solution was obtained from the test data.
TABLE 6: Response for the signal-to-noise ratio.

\begin{tabular}{lccc}
\hline Level & Load $(A)$ & Blend of fuel $(B)$ & Compression ratio $(C)$ \\
\hline 1 & -8.011 & -4.144 & -4.595 \\
2 & -5.448 & -4.280 & -4.407 \\
3 & -3.425 & -4.038 & -4.141 \\
4 & -2.071 & -4.217 & -3.757 \\
5 & -1.795 & -4.072 & -3.849 \\
Delta & 6.216 & 0.242 & 0.838 \\
Rank & 1 & 3 & 2 \\
\hline
\end{tabular}

The total mean $S / N$ ratio $\left(\overline{\gamma_{i}}\right)=-4.15$.

Finally finding of experimental study was validated with the result obtained through actual experimentation. It was concluded that B 50 blend was found to be most suitable blend for diesel engine without significantly affecting the 
TABLE 7: Results of confirmation test.

\begin{tabular}{lccc}
\hline & $\begin{array}{l}\text { Initial } \\
\text { parameter } \\
\text { combination }\end{array}$ & $\begin{array}{c}\text { Optimal parameter combination } \\
\text { Prediction } \\
(\widehat{\gamma})\end{array}$ & Experimentation \\
\hline Level & $A 3 B 3 C 3$ & \multicolumn{2}{c}{$A 5 B 3 C 4$} \\
$S / N$ ratio & -1.93950 & -1.28942 & -1.55769 \\
$\begin{array}{l}\text { Grey relation } \\
\text { grade }\end{array}$ & 0.79988 & 0.846867 & 0.835825 \\
\hline
\end{tabular}

engine performance and emissions characteristics, corresponding compression ratio and engine load being 17 and $80 \%$ respectively.

\section{Conflict of Interests}

The authors of the paper, do not have a direct financial relation with the commercial identity mentioned in their paper that might lead to a conflict of interests for any of the authors.

\section{References}

[1] C. Carraretto, A. Macor, A. Mirandola, A. Stoppato, and S. Tonon, "Biodiesel as alternative fuel: experimental analysis and energetic evaluations," Energy, vol. 29, no. 12-15, pp. 2195-2211, 2004.

[2] H. Raheman and A. G. Phadatare, "Diesel engine emissions and performance from blends of karanja methyl ester and diesel," Biomass and Bioenergy, vol. 27, no. 4, pp. 393-397, 2004.

[3] A. K. Agarwal, "Biofuels (alcohols and biodiesel) applications as fuels for internal combustion engines," Progress in Energy and Combustion Science, vol. 33, no. 3, pp. 233-271, 2007.

[4] H. Raheman and S. V. Ghadge, "Performance of compression ignition engine with mahua (Madhuca indica) biodiesel," Fuel, vol. 86, no. 16, pp. 2568-2573, 2007.

[5] H. Raheman and S. V. Ghadge, "Performance of diesel engine with biodiesel at varying compression ratio and ignition timing," Fuel, vol. 87, no. 12, pp. 2659-2666, 2008.

[6] Y. V. H. Rao, R. S. Voleti, V. S. Hariharan, and A. V. S. Ju, "Jatropha oil methyl ester and its blends used as an alternative fuel in diesel engine," International Journal of Agriculture and Biological Engg, vol. 1, pp. 32-38, 2008.

[7] S. R. Kalbande and S. D. Vikhe, "Jatropha and karanja biofuel: an alternative fuel for diesel engine," ARPN Journal of Engineering and Applied Sciences, vol. 3, pp. 7-13, 2008.

[8] G. Fontaras, G. Karavalakis, M. Kousoulidou et al., "Effects of biodiesel on passenger car fuel consumption, regulated and non-regulated pollutant emissions over legislated and realworld driving cycles," Fuel, vol. 88, no. 9, pp. 1608-1617, 2009.

[9] S. Godiganur, C. H. Suryanarayana Murthy, and R. P. Reddy, "6BTA 5.9 G2-1 Cummins engine performance and emission tests using methyl ester mahua (Madhuca indica) oil/diesel blends," Renewable Energy, vol. 34, no. 10, pp. 2172-2177, 2009.

[10] B. Baiju, M. K. Naik, and L. M. Das, "A comparative evaluation of compression ignition engine characteristics using methyl and ethyl esters of Karanja oil," Renewable Energy, vol. 34, no. 6, pp. 1616-1621, 2009.
[11] P. K. Sahoo, L. M. Das, M. K. G. Babu et al., "Comparative evaluation of performance and emission characteristics of jatropha, karanja and polanga based biodiesel as fuel in a tractor engine," Fuel, vol. 88, no. 9, pp. 1698-1707, 2009.

[12] A. Murugesan, C. Umarani, R. Subramanian, and N. Nedunchezhian, "Bio-diesel as an alternative fuel for diesel engines-a review," Renewable and Sustainable Energy Reviews, vol. 13, no. 3, pp. 653-662, 2009.

[13] M. K. Duraisamy, T. Balusamy, and T. Senthilkumar, "Experimental investigation on a mixed biodiesel fueled direct injection diesel engine," International Journal of Applied Engineering Research, vol. 5, no. 2, pp. 253-260, 2010.

[14] Y. S. Tarng, S. C. Juang, and C. H. Chang, "The use of grey-based Taguchi methods to determine submerged arc welding process parameters in hardfacing," Journal of Materials Processing Technology, vol. 128, no. 1-3, pp. 1-6, 2002.

[15] A. K. Sood, R. K. Ohdar, and S. S. Mahapatra, "Improving dimensional accuracy of fused deposition modelling processed part using grey Taguchi method," Materials and Design, vol. 30, no. 10, pp. 4243-4252, 2009.

[16] Y. Kuo, T. Yang, and G. W. Huang, "The use of a grey-based Taguchi method for optimizing multi-response simulation problems," Engineering Optimization, vol. 40, no. 6, pp. 517-528, 2008 . 

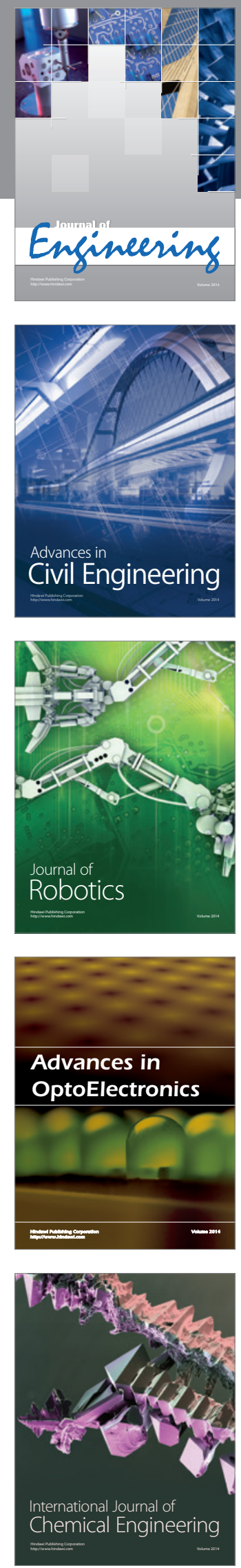

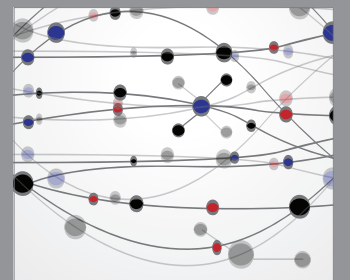

The Scientific World Journal
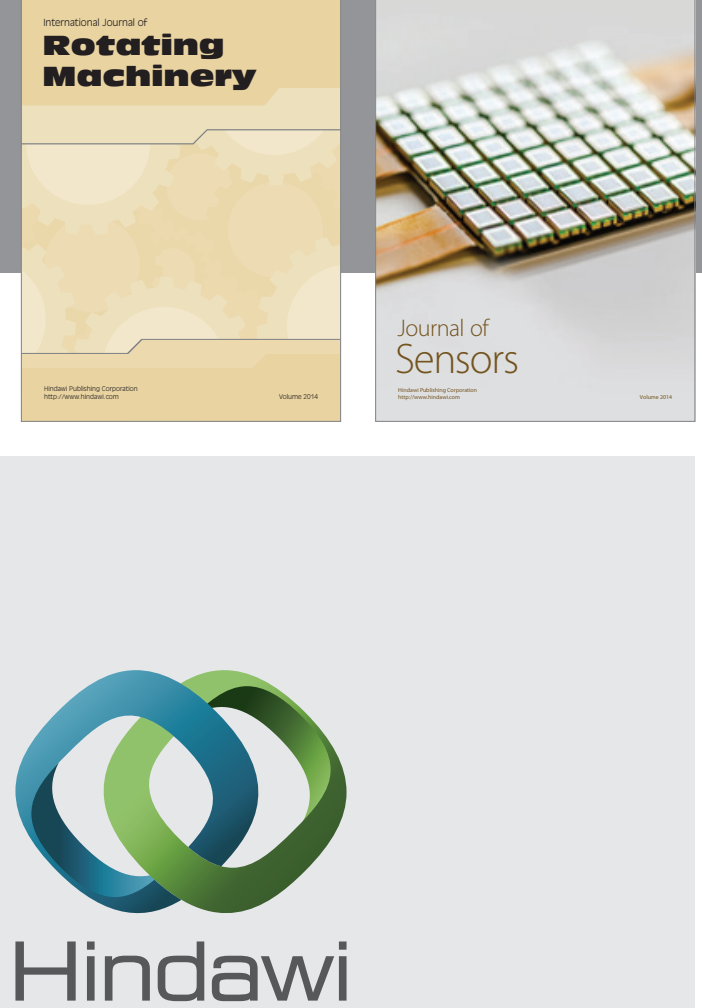

Submit your manuscripts at http://www.hindawi.com
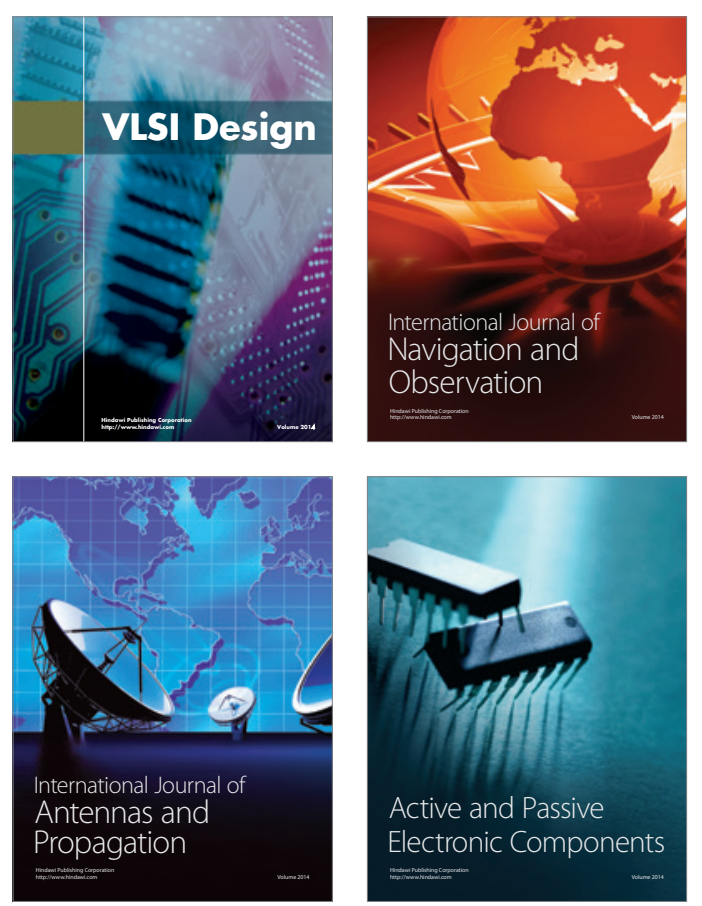
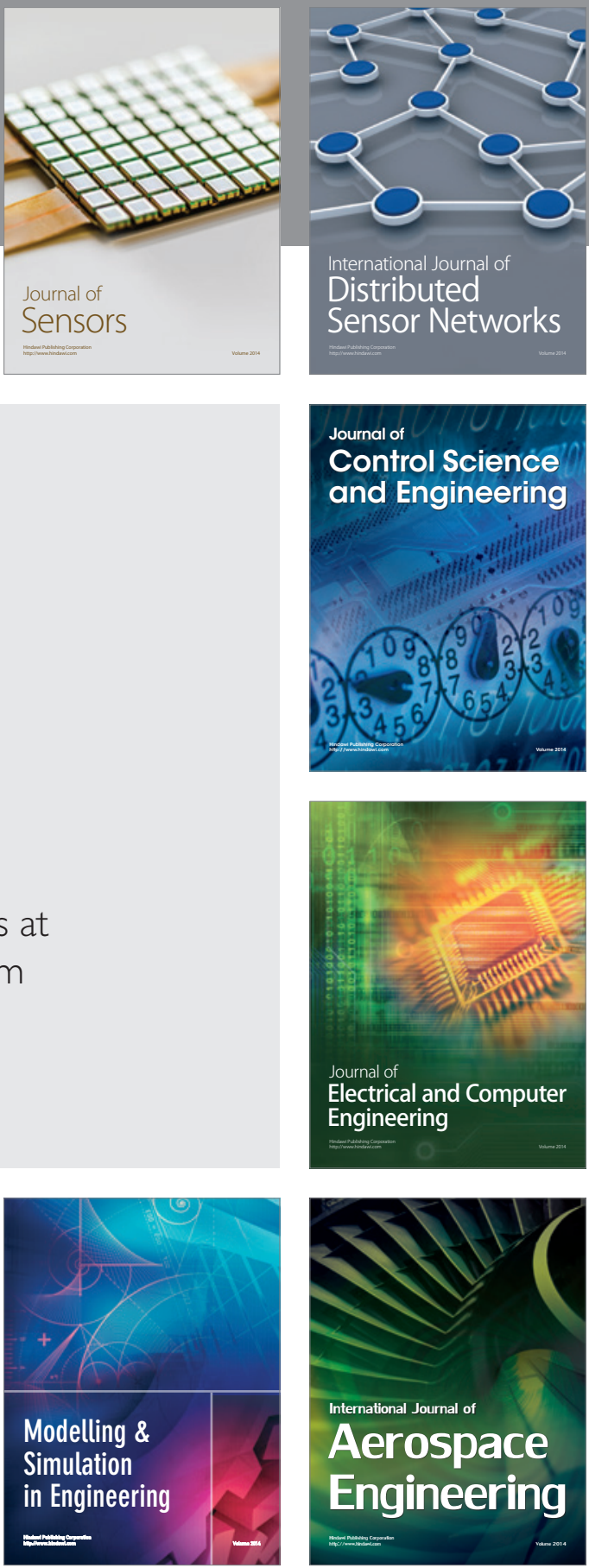

Journal of

Control Science

and Engineering
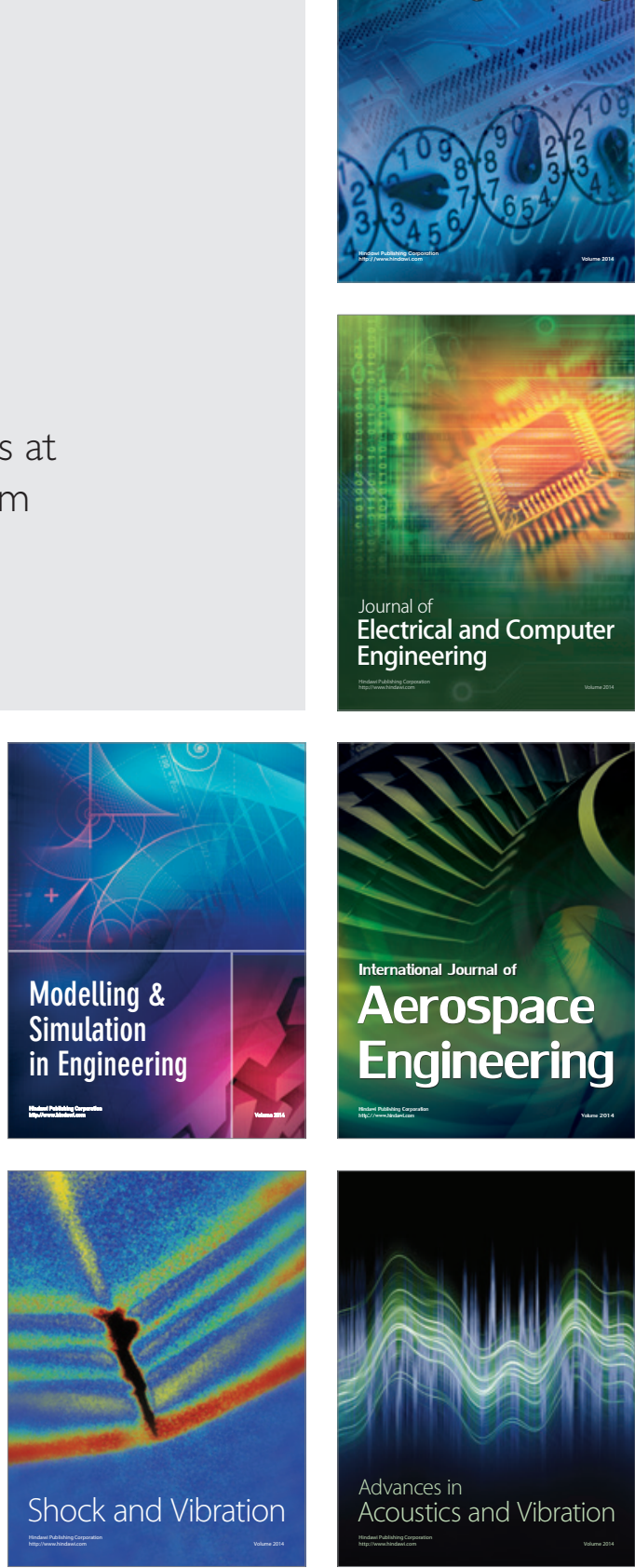